\title{
Significance of structure-property relationship in alumina based porcelain insulators to achieve quality
}

\author{
PARVATI RAMASWAMY*, S VYNATHEYA and S SEETHARAMU \\ Materials Technology Division, Central Power Research Institute, Bangalore 560 080, India
}

MS received 17 May 2005; revised 20 October 2005

\begin{abstract}
The catastrophic failures of porcelain insulators in power lines can be minimized by understanding the structure-property relationship that governs the performance. A study addressing the materials aspects has been conducted on alumina based porcelain insulators used in $25 \mathrm{kV}$ railway traction lines. This article asserts the controls exercised by chemical composition, crystalline structural phases and microstructure on the functional reliability and durability of the insulators. Influences of the total alumina, $\alpha-\mathrm{Al}_{2} \mathrm{O}_{3}$ (corundum) and $\alpha$-quartz contents, microstructural features including morphologies of mullite needles, quartz and corundum grains in the alumino silicate glassy matrix, large inhomogeneities in matrix constituents and composition have been highlighted.
\end{abstract}

Keywords. Alumina porcelain; $\% \alpha-\mathrm{Al}_{2} \mathrm{O}_{3}$; insulator; structural phase content; performance; microstructure.

\section{Introduction}

Porcelain insulators are widely used in electrical applications such as power transmission and distribution. Primarily, the function of these insulators is to insulate the distribution lines carrying electricity. Further, in applications of railway traction lines, they are also subjected to adverse environmental conditions and mechanical vibrations. Most ceramic insulators in service today are atleast 10 to 20 years old and some have lasted 70 years or more. Typically, any insulator remains in service until it breaks off or is replaced by the utility. Manufacturers generally recommend replacement after about 30 to 40 years.

Porcelain, or quartz porcelain as it is more properly called, is made of very few all-natural raw materials: quartz, feldspar and kaolin. It possesses all the major characteristics of technical ceramics, e.g. insulating capabilities, dimensional stability, hardness, thermal resistance and resistance to corrosion. Increasing demands on ceramic components for electric power generation and distribution systems and mechanical engineering uses have led to improved material properties and the development of new manufacturing methods. Replacement of quartz with alumina has yielded alumina porcelain, which is noted for its superior strength. This has been well accepted for improved product reliability and its usage has been complimented by drastic reduction in failure and quality problems experienced by insulator manufacturers (Lieberman). However, even alumina insulators manufactured (for use in $25 \mathrm{kV}$ railway traction lines) under stringent condi-

*Author for correspondence (parvi@ powersearch.cpri.res.in) tions following well-specified compositions and successfully undergoing electro-mechanical strength tests sometimes fail early during service. The period of installation before failure may vary between a few days to a few years thereby questioning the very basics of their functional reliability and the factors that govern them. Vital role in performance of the insulators is played by the ceramics that require to be tailored to suit the requirement and continued evolution in technologies to improve its performance and reliability is highly warranted. The performance is governed by basic material characteristics such as structural phases, microstructure, chemical composition, porosity and uniformity in composition (Liebermann 2001, 2003). Therefore, a study has been conducted on alumina insulators at various stages of installations in railway traction lines. They include (a) new insulators, (b) failed within a few months of installation during service and (c) removed from line after several successful years of service. The question as to what could probably cause the untimely failure of the insulators is addressed. This is aimed to bring out the materials science related influencing parameters in manufacture of alumina porcelain insulators, which are often disregarded in favour of other factors.

\section{Specimen details}

\subsection{Insulators}

Commercially available alumina body insulators were used in the study. The specimens were designated as shown in table 1 . 


\subsection{Specimens for characterization}

Specimens of about $25 \mathrm{~cm}^{2}$ were cut from the ceramic core of the insulators using diamond tipped cut off wheel. These pieces (after ultrasonic cleaning) were used for both qualitative X-ray diffractometry (XRD) and quantitative energy dispersive X-ray (EDX) analysis (with mild carbon coating for conduction purposes in SEM). Finely powdered specimens mixed with suitable additives were used for quantitative phase analysis using XRD. The cut specimens were ground, polished and etched metallographically and coated with a thin film of gold for SEM microstructural studies. Micro hardness and fracture toughness studies were carried out on polished and etched specimens.

\section{Characterization}

Qualitative and quantitative structural phase analyses were carried out by XRD. Internal standard method was used for the quantitative estimation of $\alpha-\mathrm{Al}_{2} \mathrm{O}_{3}$ and $\alpha$-quartz by XRD (Klug and Alexander 1948; Cullity 1978). Scanning electron microscope and energy dispersive X-ray analysis (SEM/EDX) were employed for microstructure, defect morphological studies and chemical composition analysis. Microhardness was determined by the Vickers indentation method (HV1.0) on polished specimen. Atleast ten areas were studied for micro hardness on each specimen and average results pertaining to values lying within a standard error of 5\% have been reported. By observing the cracks generated at the indenting load of $10 \mathrm{kN}$, fracture toughness studies were carried out in a qualitative manner.

\subsection{Determination of $\% \alpha$-quartz and $\% \alpha-\mathrm{Al}_{2} \mathrm{O}_{3}$}

Calibration curves (by XRD) for quantitative estimation of the desired phases ( $\alpha$-quartz and $\alpha-\mathrm{Al}_{2} \mathrm{O}_{3}$ ) have been prepared using standard samples of $\alpha$-quartz $(99.5+) \%$, and $\alpha-\mathrm{Al}_{2} \mathrm{O}_{3}(99.5+) \%$. Suitable diluents (calcite for $\alpha$ quartz and $\mathrm{TiO}_{2}$ for $\alpha-\mathrm{Al}_{2} \mathrm{O}_{3}$ ) and additives $(\mathrm{ZnO}$ for $\alpha$ quartz and $\mathrm{CaF}_{2}$ for $\alpha-\mathrm{Al}_{2} \mathrm{O}_{3}$ ) were used to prepare the desired standard compositions (from 5 to $100 \%$ ). The calibration curve was generated from the XRD using the intensity ratio of the strong relevant peaks for each composition. The insulator samples to be analysed for $\alpha$ quartz and $\alpha-\mathrm{Al}_{2} \mathrm{O}_{3}$ contents also were prepared using the corresponding additives. Using the intensity ratios, the $\% \alpha$-quartz and $\% \alpha-\mathrm{Al}_{2} \mathrm{O}_{3}$ were derived from the respective calibration curves. This well known method (Klug and Alexander 1948; Cullity 1978) introduces an error of $<3 \%$ in the quantitative estimation of the crystalline phases provided the additives and diluents are chosen suitably such that there are no overlapping peaks and the specimens are prepared carefully.

\section{Results and discussion}

\subsection{Structural phases and chemical composition}

Qualitative XRD analysis of the insulators showed the presence of all or a few of the following crystalline phases in a glassy matrix: (a) $\alpha-\mathrm{Al}_{2} \mathrm{O}_{3}$ (corundum phase), (b) $\alpha$ quartz $\left(\mathrm{SiO}_{2}\right)$ and (c) $3 \mathrm{Al}_{2} \mathrm{O}_{3} \cdot 2 \mathrm{SiO}_{2}$ (mullite). Details are given in table 2.

Both $\mathrm{A}$ and $\mathrm{D}$ appear identical in their crystalline structural make up. Mullite appears as a major phase in B unlike the other insulators, where mullite is present as a minor phase only. $\alpha$-Quartz is present as major phase in both $\mathrm{B}$ and $\mathrm{C}$.

Figure 1 shows the calibration curves prepared by $\mathrm{X}$ ray diffraction method for (a) $\alpha$-quartz and (b) $\alpha-\mathrm{Al}_{2} \mathrm{O}_{3}$,

Table 1. Specimen designations.

\begin{tabular}{lcl}
\hline S1. no. & Designation* & \multicolumn{1}{c}{ Status of installation } \\
\hline 1 & A & Removed from line after good service for nearly 15 years \\
2 & B & Failed before commissioning \\
3 & C & Failed in service within 6 months of commissioning \\
4 & D & Failed in service within 8 years of commissioning \\
\hline
\end{tabular}

*Many insulators (atleast 10) have been studied under each category designated.

Table 2. Crystalline structural phases (qualitative).

\begin{tabular}{llc}
\hline & \multicolumn{2}{c}{ Phases present } \\
\cline { 2 - 3 } Designation & \multicolumn{1}{c}{ Major } & Minor \\
\hline $\mathrm{A}$ & Corundum & Mullite \\
$\mathrm{B}$ & Mullite, corundum, $\alpha$-quartz & - \\
$\mathrm{C}$ & Corundum, $\alpha$-quartz & Mullite \\
$\mathrm{D}$ & Corundum & Mullite \\
\hline
\end{tabular}


respectively. Percentages of the desired unknown phases were obtained directly from the calibration graphs from the slopes of the straight lines, and the intensity of the constituent phases. Attempts were not made to estimate the mullite contents quantitatively. This was both because mullite appeared as a minor phase in most of the insulators and also the difficulty associated with the search of suitable diluents and additives to eliminate overlapping peaks.

Table 3 shows the quantitative phase contents of the insulators i.e. total $\mathrm{Al}_{2} \mathrm{O}_{3}$ and other oxides (of $\mathrm{Fe}, \mathrm{Ca}$ and $\mathrm{Ti}$ either as impurities/additional phases) obtained by EDX along with $\% \alpha-\mathrm{Al}_{2} \mathrm{O}_{3}$ and $\% \alpha$-quartz, obtained from XRD. Both specimens $\mathrm{A}$ and $\mathrm{D}$ possess higher total alumina (up to $45 \%$ ) and $\% \alpha-\mathrm{Al}_{2} \mathrm{O}_{3}$ contents (up to $34 \%$ ) compared to the specimens $\mathrm{B}$ and $\mathrm{C}$, which have shown much inferior performance. Correspondingly, the $\alpha$ quartz contents in $\mathrm{A}$ and $\mathrm{D}$ are lower $(<2 \%)$ too. $\% \alpha-$ $\mathrm{Al}_{2} \mathrm{O}_{3}$ and $\% \alpha$-quartz appear to be important guiding factors which contribute towards a reliable service in addition to the total alumina content in the body. However, the relatively lower service life $(\sim 8$ years) of specimens categorized as D cannot be explained based on these parameters alone. This is because specimen D is identical to specimen $\mathrm{A}$ in its chemistry. Further, presence of other oxides of $\mathrm{Fe}$, Ti etc in larger quantities $(\sim 3 \%)$ in specimens $\mathrm{B}$ and $\mathrm{C}$ (compared to $\mathrm{A}$ and $\mathrm{D}$ ), may also not be desirable for performance.
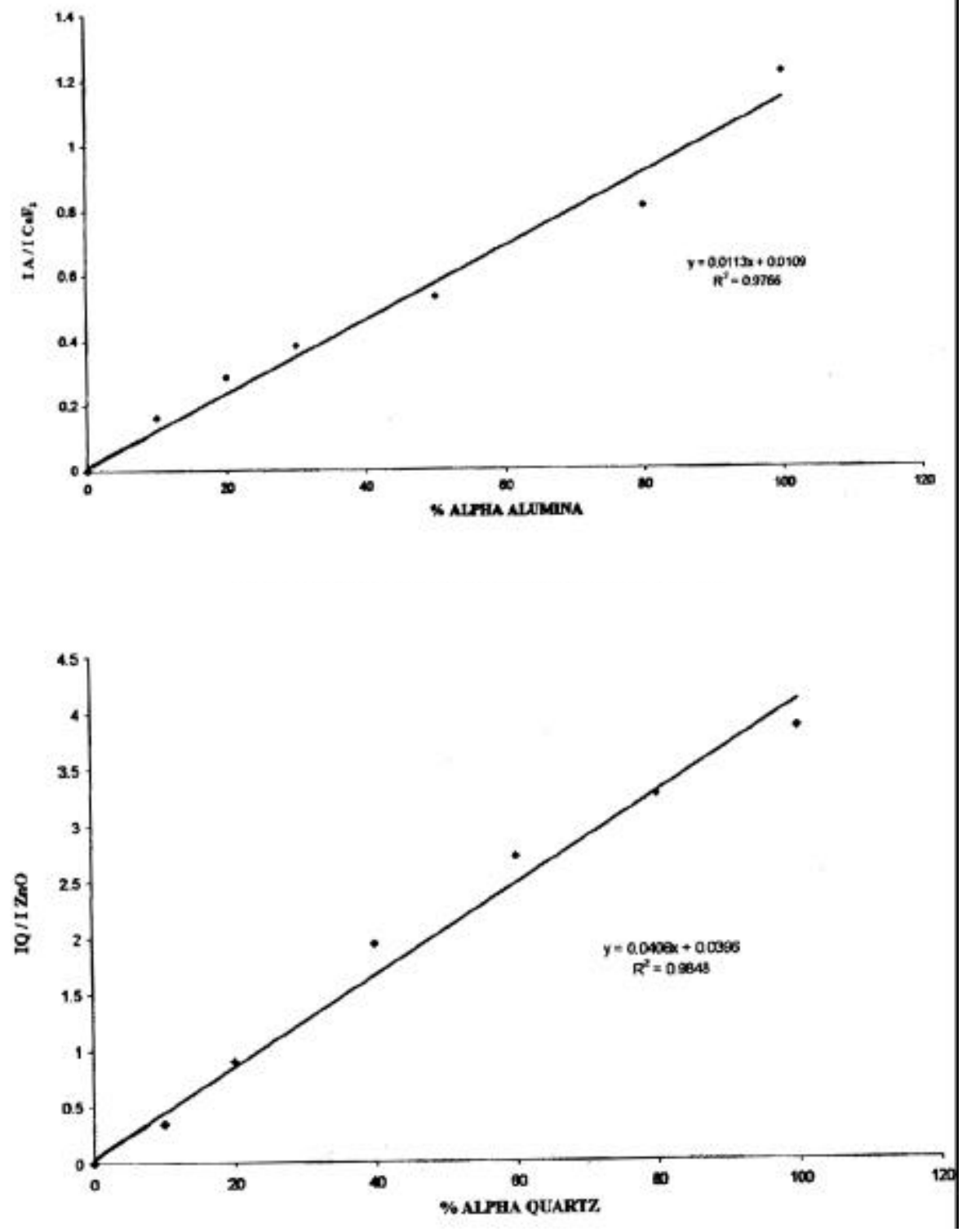

Figure 1. Calibration curves for $\alpha-\mathrm{Al}_{2} \mathrm{O}_{3}$ and $\alpha$-quartz. 
Table 3. Crystalline and total phases (quantitative).

\begin{tabular}{lcccc}
\hline Designation & $\begin{array}{c}\% \\
\text { Total } \mathrm{Al}_{2} \mathrm{O}_{3}\end{array}$ & $\alpha-\mathrm{Al}_{2} \mathrm{O}_{3}$ & $\begin{array}{c}\% \\
\alpha \text {-Quartz }\end{array}$ & $\begin{array}{c}\text { Other oxides } \\
(\mathrm{Fe}, \text { Ti etc) }\end{array}$ \\
\hline $\mathrm{A}$ & $42-45 \cdot 0$ & $32-34 \cdot 0$ & $<2 \cdot 0$ & $<0 \cdot 75$ \\
$\mathrm{~B}$ & $33-34 \cdot 0$ & $19-20 \cdot 0$ & $10 \cdot 0$ & $3 \cdot 0$ \\
$\mathrm{C}$ & $35-37 \cdot 0$ & $27-28 \cdot 0$ & $8 \cdot 0$ & $3 \cdot 0$ \\
$\mathrm{D}$ & $42-45 \cdot 0$ & $32-34 \cdot 0$ & $<2 \cdot 0$ & $<1 \cdot 0$ \\
\hline
\end{tabular}

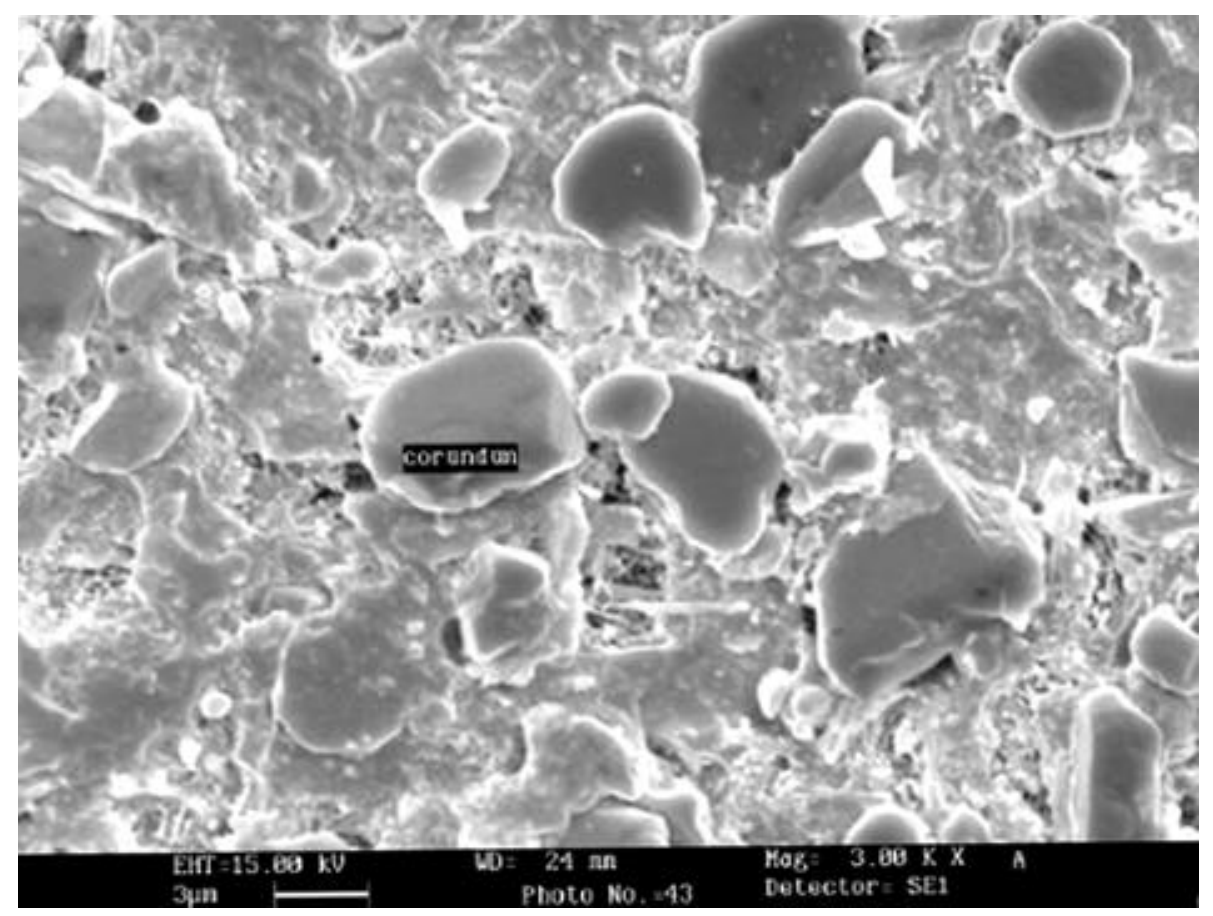

Figure 2. SEM micrograph of insulator A (removed from line after 15 years) at $3000 \times$.

\subsection{Micro hardness}

Table 4 shows the micro hardness values obtained for the insulators in the matrix (avoiding corundum and $\alpha$-quartz phases). The superiority of the porcelain matrix of specimen $\mathrm{A}$ and the favourable influence of corundum $\left(\alpha-\mathrm{Al}_{2} \mathrm{O}_{3}\right)$ with respect to the other insulators under study is evident from its high value of micro hardness. While specimens $\mathrm{B}$ and $\mathrm{C}$ showed expectedly lower values of micro hardness, the values in specimen $\mathrm{D}$ (also with high corundum content like specimen A) varied widely between the various randomly analysed regions unlike the other three categories of insulators.

\subsection{Scanning electron microscopy}

SEM micrographs pertaining to the representative specimens and salient features observed are as follows.

Micrograph (figure 2) of polished and etched specimen A (removed from line) shows a well-sintered porcelain
Table 4. Vickers micro hardness.

\begin{tabular}{lc}
\hline Designation & HV1.0 \\
\hline A & 741 \\
B & 462 \\
C & 513 \\
D & $571-666$ \\
\hline
\end{tabular}

matrix with uniform distribution of almost round (not angular with sharp edges) shaped reinforcements of sintered corundum $\left(\alpha-\mathrm{Al}_{2} \mathrm{O}_{3}\right)$ phase. The corundum grains measure between 2 and $8 \mu \mathrm{m}$. This is associated with a good distribution of clusters of fine $(\sim 1 \mu \mathrm{m}$ long and width not more than $0.1 \mu \mathrm{m}$ ) needle shaped structures (mullitic in nature). While the corundum phase may be the most desirable phase to resist the propagation of cracks in the porcelain matrix, fine needles of mullite in restricted quantity may not be harmful to the body. The sintering and heat treatment often promotes formation of mullite and may invariably be unavoidable. 
Figure 3 shows the micrograph of a body made of predominantly needle like mullitic structures. This belongs to specimen $\mathrm{B}$ which has failed before being commissioned in line. Qualitative XRD analysis (table 2) has confirmed the presence of mullite as a major phase in these insulators. These structures are coarse $(8-10 \mu \mathrm{m}$ long and width, $0 \cdot 5-0.8 \mu \mathrm{m}$ ) when compared to those observed in the clusters of specimen A. It becomes evident that the poor service offered by this batch of insulators is attributed to their low $\alpha-\mathrm{Al}_{2} \mathrm{O}_{3}$ content combined with coarse grained high mullite content. It is likely that the mullite needles have been generated by sintering schedules (or heat treatments) not suitable for insulator manufacture causing the sacrifice of corundum phase.

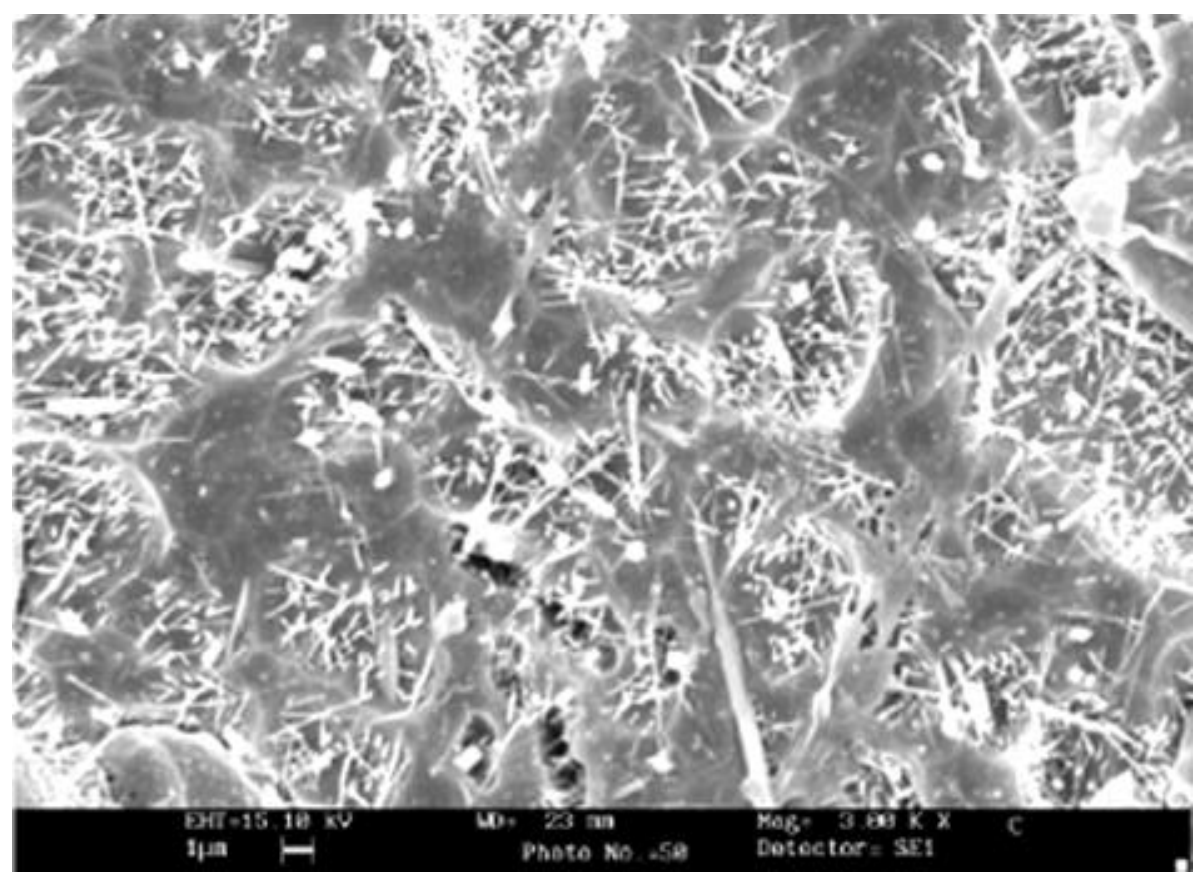

Figure 3. SEM micrograph of insulator B (failed before commissioning) at 3000×.

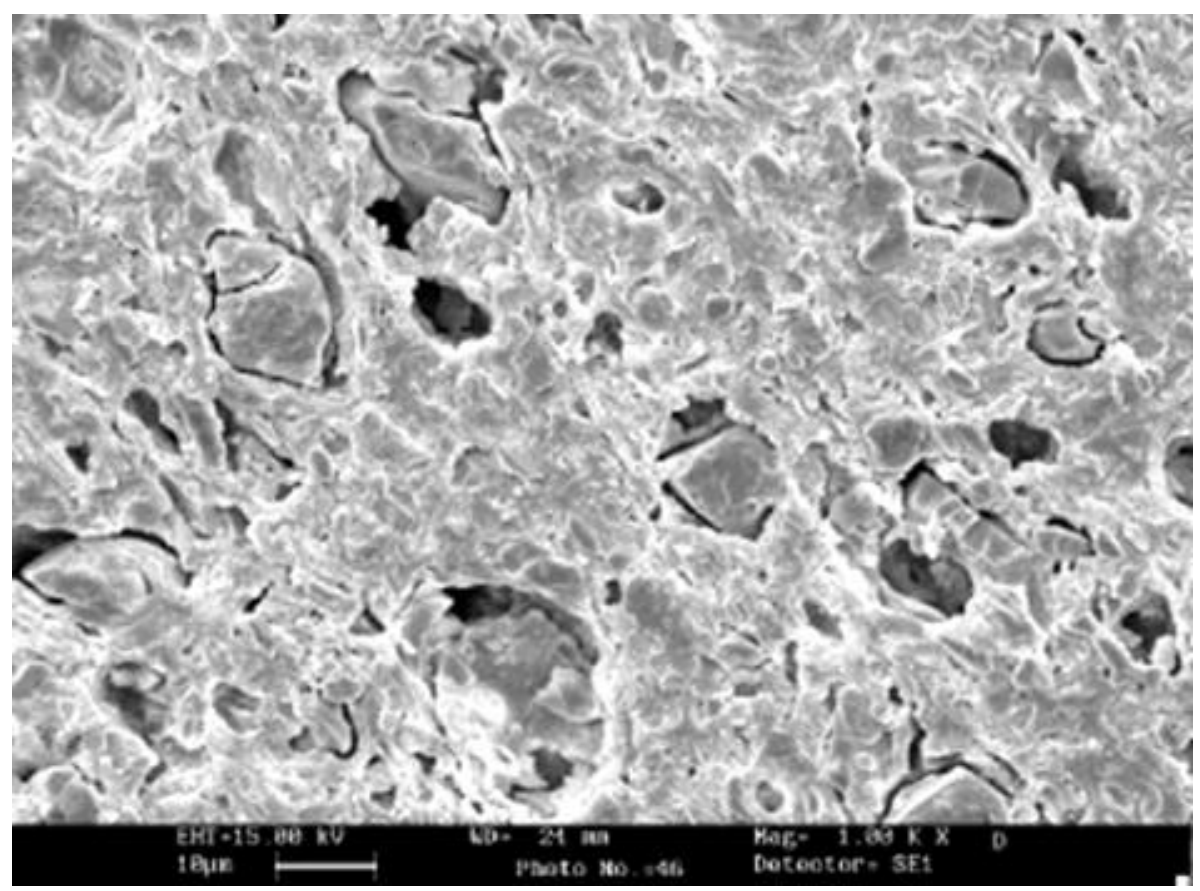

Figure 4. SEM micrograph of insulator $\mathrm{C}$ (failed in service within 6 months of commissioning) at $1000 \times$. 
Figure 4 shows the micrograph of specimen $\mathrm{C}$ (failed in service in six months) depicting presence of coarse $\alpha$ quartz particles with both inter and intragranular cracks in the porcelain matrix. This phase may be a detrimental factor because it appears to generate voids at the grain boundaries within the porcelain matrix.

The microstructure of specimen $\mathrm{D}$ (failed in service after 8 years) shown in figures $5 \mathrm{a}$ and $\mathrm{b}$ (at 3000x and 2000x, respectively), show pockets of either loosely held corundum grain platelets or large voids (depicting grain pullouts) in the matrix. The sizes of the corundum grains in sample $\mathrm{D}(\sim 12 \mu \mathrm{m})$ are relatively larger than those of sample $\mathrm{A}(\sim 6 \mu \mathrm{m})$. The voids are also of similar dimensions. This insulator although, is identical to specimen $\mathrm{A}$ in terms of total alumina and $\alpha-\mathrm{Al}_{2} \mathrm{O}_{3}$ contents, the cause for its poor service reliability seems to lie in its mi-
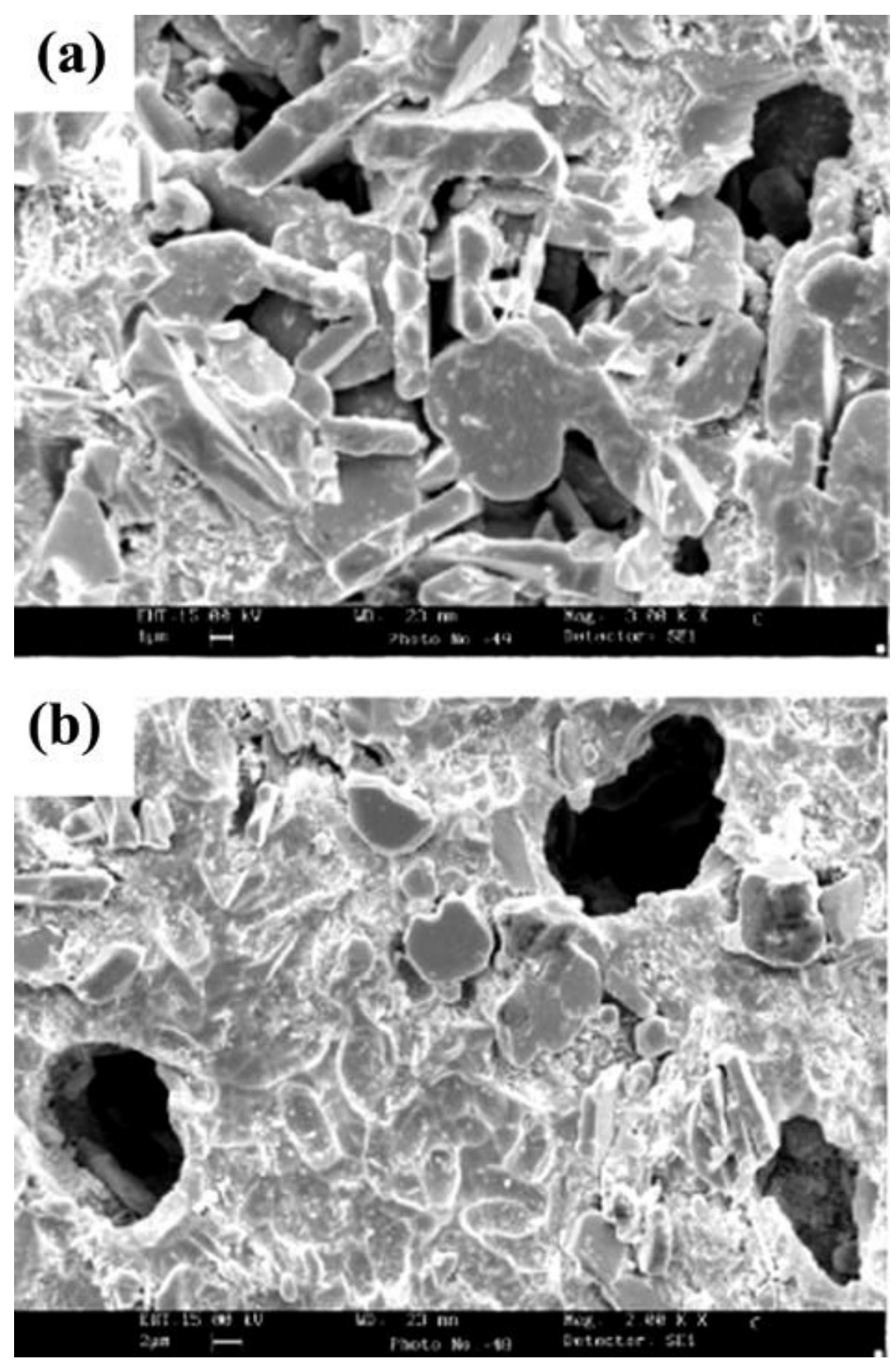

Figure 5. SEM micrographs of insulator D (failed in service after 8 years) at (a) $3000 \times$ and (b) 2000x. 


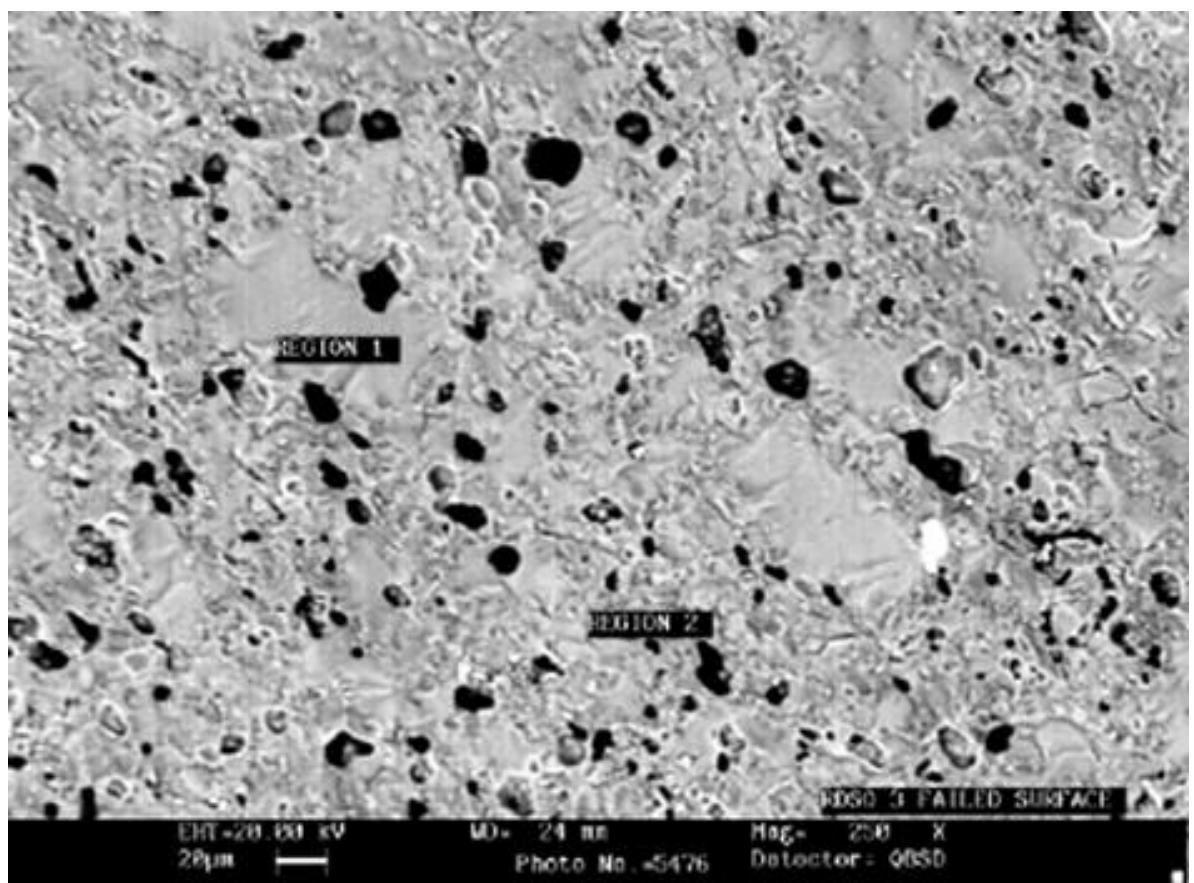

Figure 6. SEM micrograph of D (failed in service after 8 years) at $250 \times$.

Table 5. Chemical composition of two regions (smooth and rough) in failed surface of D.

\begin{tabular}{ll}
\hline Region 1 (smooth) & Region 2 (rough) \\
\hline $\mathrm{Al}_{2} \mathrm{O}_{3} \sim 20 \%$ & $\mathrm{Al}_{2} \mathrm{O}_{3} \sim 50 \%$ \\
$\mathrm{SiO}_{2} \sim 70 \%$ & $\mathrm{SiO}_{2} \sim 40 \%$ \\
$\mathrm{~K}_{2} \mathrm{O} \sim 7 \%$ & $\mathrm{~K}_{2} \mathrm{O} \sim 3 \%$ \\
$\mathrm{Na}_{2} \mathrm{O} \sim 2 \%$ & $\mathrm{Na}_{2} \mathrm{O} \sim 1 \%$ \\
$\mathrm{Fe}_{2} \mathrm{O}_{3} \sim 2 \%$ & $\mathrm{Fe}_{2} \mathrm{O}_{3} \sim 1 \%$ \\
\hline
\end{tabular}

crostructure. An interesting observation is the presence of inhomogeneities in the chemical composition of the matrix region (without corundum grains). The SEM micrograph depicting these features is shown in figure 6 (at $250 \times$ ). On closer observation, non-uniformity is observed both in microstructure and in the chemical composition of the matrix (in regions other than corundum and mullite), where it is expected to be consistent. Typical composition of two regions (smooth and rough) on the surface of the core of specimen $\mathrm{D}$ is shown in table 5 . The region 1 is glassier with high silica content while the other region is similar to the desired high alumina content in porcelain structure. The effect of inhomogeneous microstructure is also reflected in the variation in micro hardness (table 4). However, on an average the percentage phases (high corundum and low quartz content) apparently match well with the insulator removed from line without failure i.e. A (table 3). These results further lend support to the key role played by homogenous phase distribution in providing life and stability to the insulator.

\subsection{Fracture toughness}

Figure 7 shows SEM micrographs of polished and etched specimens A (figure 7a) and C (figure 7b) which have been subjected to micro hardness indents $(10 \mathrm{KN}$ load) for studying fracture toughness. It was not possible to measure the crack lengths owing to their zigzag nature and also to calculate the fracture toughness of any specimen. Hence, an attempt has been made to grade them relatively with respect to each other. In general, it was observed that specimen A showed improved resistance to cracking with respect to $B$ and $C$. The specimens which have failed early showed plastic deformation and large cracks in and around the indents. Figure $7 \mathrm{c}$ shows the cracks at the tip of indent in specimen $\mathrm{C}$.

\section{Conclusions}

The present investigation involves railway traction line insulators among which some have served reliably and also 

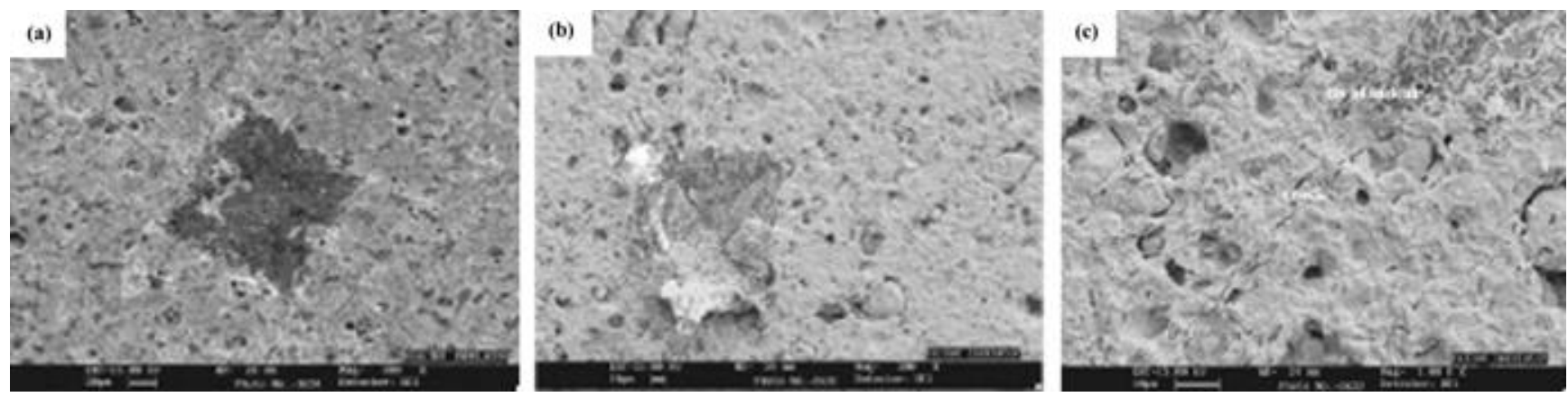

Figure 7. SEM micrographs of insulators (a) A, (b) $\mathrm{C}$ at $300 \times$ (showing micro hardness indents at $10 \mathrm{kN}$ load) and (c) $\mathrm{C}$ at $1000 \times$ (showing cracks at tip of indent at $10 \mathrm{KN}$ load).

those which have failed early. From the results, the following conclusions are drawn.

(I) While the total alumina $\left(\mathrm{Al}_{2} \mathrm{O}_{3}\right)$ content appears to optimize and assure better performance in alumina based porcelain insulator (with respect to quartz based insulator), the key deciding factor contributing to long term reliable service is the corundum phase i.e. the total $\alpha$ $\mathrm{Al}_{2} \mathrm{O}_{3}$ content.

(II) Homogenous distribution of $\alpha-\mathrm{Al}_{2} \mathrm{O}_{3}$ plays an important role in determining the long term reliable service life of the insulator.

(III) To ensure improved resistance to propagation of defects, $\alpha$-quartz content should be minimized in the porcelain matrix.

(IV) The observations are extrapolated to construe to the possible conclusion that the microstructure should be controlled through sintering and heat treatment processes such that only fine mullite needles are formed to a limited extent and uniformly distributed in the matrix. Mullite formation sacrificing corundum should not be allowed. (V) Impurities which arise out of raw materials (like oxides of $\mathrm{Fe}$ etc) should be restricted to $<1.0 \%$.

\section{Acknowledgement}

Research Designs and Standards Organization, Lucknow, is specially thanked for providing the insulators.

\section{References}

Cullity B D 1978 Elements of X-ray diffraction (Reading, MA: Addison-Wesley Publishing Co) 2nd ed., p. 415

Klug H P and Alexander L E 1948 Anal. Chem. 20886

Liebermann J 2001 Am. Ceram. Soc. Bull. 8037

Liebermann J 2003 Am. Ceram. Soc. Bull. 8239 